OPEN

SUBJECT AREAS:

FISHERIES

ECOSYSTEM ECOLOGY

ECOSYSTEM SERVICES

CONSERVATION

Received

9 October 2012

Accepted

29 January 2013

Published

25 February 2013

Correspondence and requests for materials should be addressed to

E.V.

(enriqueta_velarde@ yahoo.com.mx)

\section{Seabird diets provide early warning of sardine fishery declines in the Gulf of California}

\author{
Enriqueta Velarde', Exequiel Ezcurra ${ }^{2} \&$ Daniel W. Anderson ${ }^{3}$
}

\begin{abstract}
'Instituto de Ciencias Marinas y Pesquerías, Universidad Veracruzana, Boca del Río, Veracruz 94290, Mexico, ${ }^{2}$ Department of Botany and Plant Sciences, University of California, Riverside (UCR), Riverside, CA 92521, USA, ${ }^{3}$ Department of Wildlife, Fish, \& Conservation Biology, University of California, Davis; Davis, CA 95616, USA.
\end{abstract}

Small pelagic fisheries show wide fluctuations, generally attributed to oceanographic anomalies. Most data on these fisheries come from landings, often reporting sustained catches-per-unit-effort (CPUEs) until a decline occurs. Fishery-independent data are important as management tools. In this study we show that the proportions of Pacific Sardine and Northern Anchovy in the diet of three seabird species (California Brown Pelicans, Heermann's Gulls, and Elegant Terns) nesting in spring in the Gulf of California show significant relationships with CPUEs during the following season in gulls and terns, or during the same season in pelicans. As sardine availability for seabirds declines, CPUEs remain high until the fishery falls, one or two seasons later. A declining proportion of sardines in the seabirds' diet, combined with the status of the Pacific warm-phase anomaly (El Niño), give a reliable forecast of diminishing CPUEs and signals the need to reduce fishing efforts in the ensuing season.

$\mathrm{n}$ upwelling regions, such as the California, Humboldt, and Benguela current systems, fishing industries capture the same fish species that seabirds and other marine species feed upon. These small pelagic fishes (known as "forage fish") constitute ca. $37 \%$ of the world's commercial landings ${ }^{1,2}$, and often show wide fluctuations, generally attributed to oceanographic-anomalies ${ }^{3-5}$. Key components of the coastal pelagic marine ecosystem ${ }^{6}$, their fisheries have been difficult to manage sustainably ${ }^{2,7}$, and regional economies have been shaken by their collapses ${ }^{1}$. Forage fish transfer energy from microscopic plankton to larger predators and constitute a fundamental food source for marine mammals, seabirds ${ }^{8-10}$, and larger fish species, many of which are also commercially important ${ }^{4,7}$.

Comprehensive models have been developed describing the often non-linear relationship between CPUE and fishery-independent estimates of stock size, fishery abundance, or availability ${ }^{11-15}$, but in the Gulf of California there are no robust fishery-independent stock assessments available for small pelagic fisheries. Seabirds, however, face similar challenges as does the fishing fleet to find available prey and harvest it. Many studies have shown relationships between seabird diet and fisheries' parameters, and used them as a tool to monitor the fish species on which the seabirds feed ${ }^{8,9,11,14,16,17,19}$. A recent study by Cury et al. ${ }^{6}$ identified a world-wide threshold in forage fish abundance below which seabirds experience consistently reduced breeding success. Among other indicators of fish abundance for this global study, they used the proportion of adult Red-billed Gulls which regurgitated krill when captured, as an estimator of krill abundance in New Zealand. Similarly, members of our own research team developed a predictive model linking the proportion of Pacific Sardine in the seabirds' diet with both total catch and CPUE for the commercial fleet ${ }^{10}$. Studying the impact of El Niño anomalies in the Gulf of California, we have also shown that seabird breeding success is severely reduced by warm-phase oceanographic anomalies when the increased thermocline depth prevents seabirds from reaching their prey ${ }^{18}$. Lastly, after an abrupt fall in sardine landings in the Gulf of California in 1990, the sardine total catch lost the positive relationship it had exhibited with the fishing effort and has now followed a strongly fluctuating pattern with increasing amplitudes (Fig. 1). Among other potential fishery management tools, we test here whether these fluctuations could be better understood and forecasted using seabird diet composition as a simple monitoring variable.

We analysed the statistical behaviour of CPUE of two small pelagic fishes in the Midriff Region of the Gulf of California, Mexico (Fig. 2; a detailed description of our study region is presented as Supplementary Information): Pacific Sardine (Sardinops sagax) and Northern Anchovy (Engraulis mordax), compared against their proportion in the diet of three seabird: Elegant Tern (Thalasseus elegans), Heermann's Gull (Larus heermanni) and California 


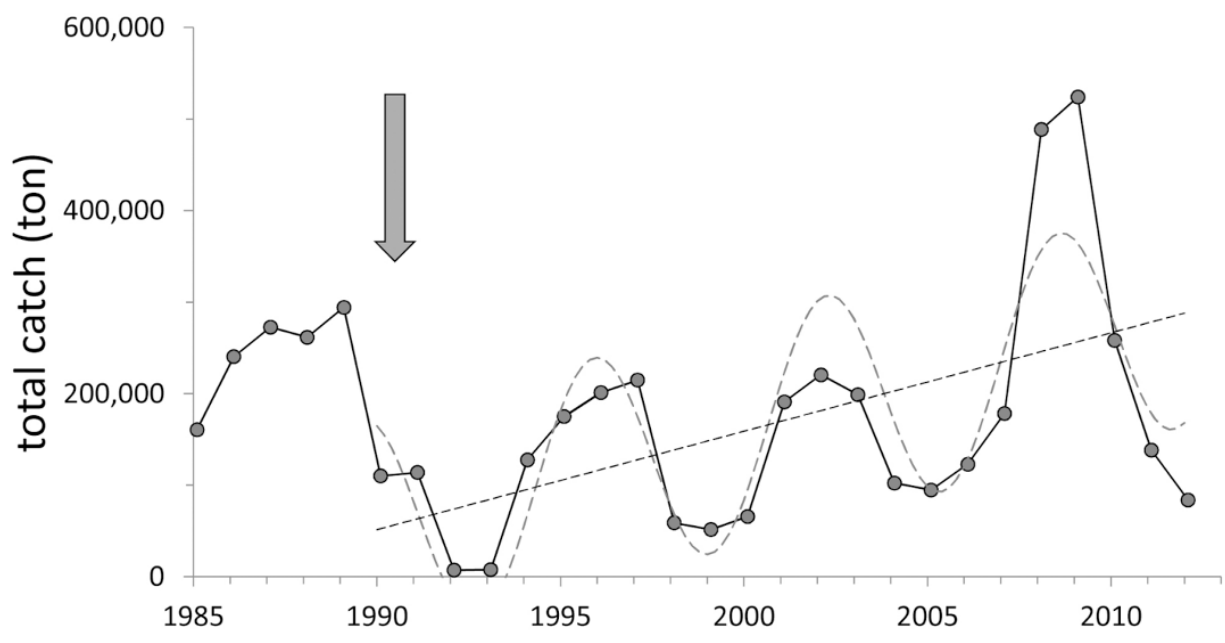

Figure 1 | Total sardine landings in the Gulf of California between 1970 and 2011. The arrow shows the first sharp fall in fishery landings, in 1990. After that point, the fishery has followed a quasi-cyclic pattern with a 6-year period. The dotted lines between 1990 and 2011 show the general time-series linear trend (partial $r^{2}=0.29 ; P=0.003$ ) and the fitted periodic oscillation (partial $r^{2}=0.47 ; P<0.001$ ).

Brown Pelican (Pelecanus occidentalis californicus). Our driving question was: Do all forage fish species have similar catchability for the fleet as they have for seabirds? Or, alternatively, does the fleet have the capacity to maintain high CPUEs for certain fishes even as their availability declines for seabirds?

\section{Results}

The main target of the fishing fleet in the Gulf of California is the Pacific Sardine, which constitutes more than 55\% of the regional catch. Northern Anchovies, on the other hand, are avoided by the fleet because of their lower commercial value, and form on average less than $2 \%$ of the catch. As sardine availability fluctuates, the three seabird species shift in synchrony from a diet rich in sardine to a diet rich in anchovy (Fig. 3 and Supplementary Information Table 1).

A correlogram between seabird diets and CPUE showed that, for Elegant Terns and Heermann's Gulls a lag of one season produced the highest correlations between variables; seabird diets in spring (April-June) showed the strongest correlations with CPUE for the fishing season starting five months later, in October, and ending in summer (July) of the following year. Pelicans, in contrast, showed the highest correlations with same-season CPUEs (Supplementary Information Table 2).

In the case of sardines, the relationship between seabird diets and CPUEs was best modelled by a simple linear equation with an intercept of ca. 40 tonnes per boat-day (Fig. 4). That is, as the proportion

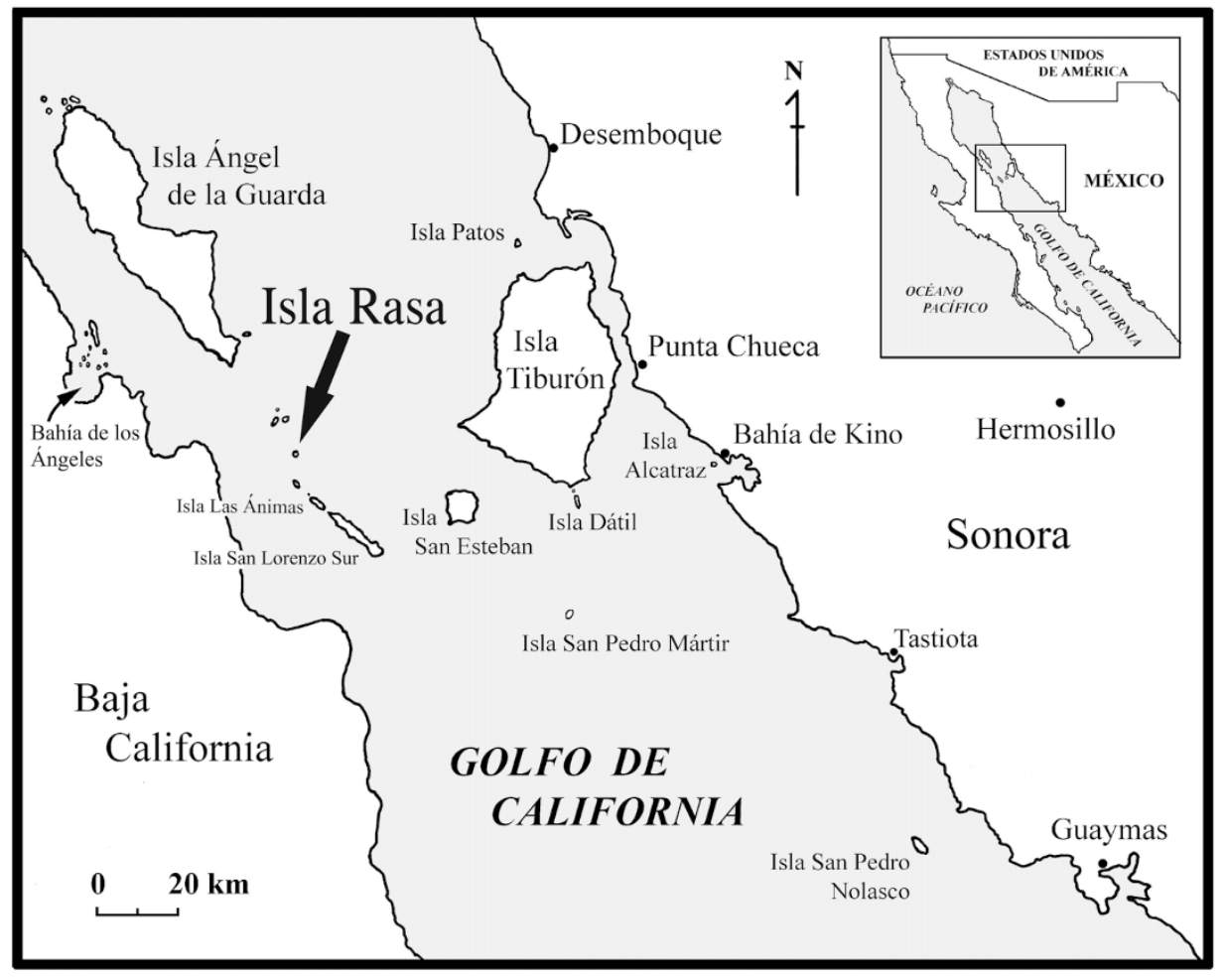

Figure $2 \mid$ Map of the Midriff Islands, Gulf of California, Mexico, indicating the location of Isla Rasa and other islands (drawn by Cathy Moser Marlett). 


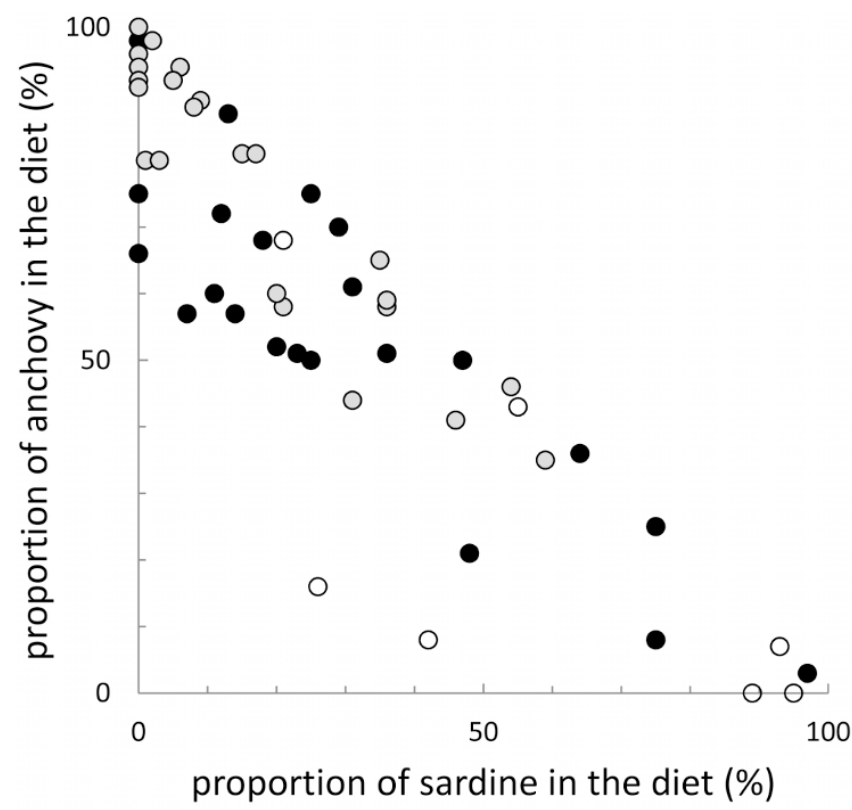

Figure 3 Relationship between the proportions of Pacific Sardine and Northern Anchovy in the diet of the three seabird species, for different years between 1983 and 2005. Gray data points correspond to Elegant Terns, black points to Heermann's Gulls, open points to Brown Pelicans. Jointly, Pacific Sardines and Northern Anchovies formed on average the majority of the seabirds' diet: $83 \%$ of the diet in the Brown Pelicans, $87 \%$ in the Heermann's Gulls, and $92 \%$ in the Elegant Terns (the third most consumed species was the Pacific Mackerel).

of sardines in the seabirds' diet decreases, the CPUE by the fishing fleet decreases gradually until, when seabirds cease taking sardines entirely, the fleet is still fishing in significant numbers, ca. 40 tonnes per day. In the case of anchovies, the best model for Elegant Terns and Heermann's Gulls was provided by a power-function in which the functional relationship between the proportion of anchovy in the seabirds' diets against the one-season-lagged CPUE values was markedly concave (Fig. 5), revealing a significant non-linear relationship between both variables. For these two seabird species, as the proportion of anchovies increases in their diets, the fleet's CPUEs still remain near zero, and it is only until seabirds start feeding almost exclusively on anchovies that the fleet starts catching them in any significant amount. In contrast, proportion of anchovy in the Brown Pelican diet showed a significant linear fit with anchovy CPUEs during the same season in which diets were estimated.

The sensitivity of the seabird diets relative to CPUE can also be seen in the coefficients of variation $(c v)$ of both series. In the case of sardines, the relative variation in seabird diets was in all cases almost double that that of CPUE values, indicating that, in relative terms, the seabirds vary more in their sardine consumption than the fleet does in its CPUEs. In the case of anchovies the situation was reversed: $c v$ values in seabird diets were much lower than for CPUEs, indicating that seabirds are more constant than the fleet in their anchovy consumption (Supplementary Information Table 3).

Finally, we found that, jointly, the proportion of fish in the diets of gulls and terns, and the Southern Oscillation Index (SOI) significantly predicted sardine CPUE in the following season (Supplementary Information Table 4). In contrast, the SOI was not a significant predictor of anchovy CPUE.

\section{Discussion}

The relationship between the proportion of sardine in the seabird diets and sardine CPUE shows that sardine catchability decreases faster for seabirds than it does for the fleet, which can maintain high

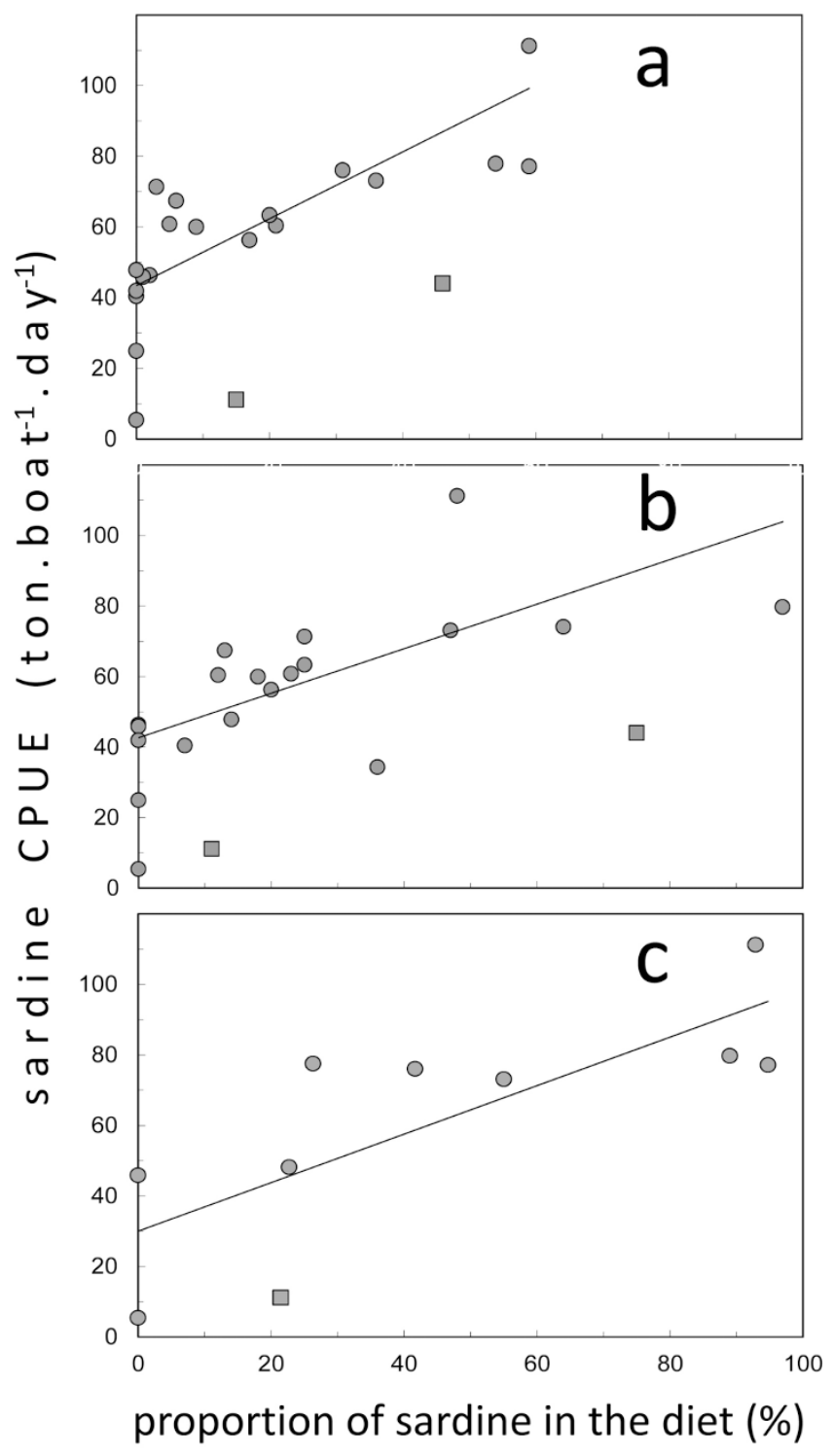

Figure $4 \mid$ Linear relationship between proportion of Pacific Sardine in the seabirds' diet and CPUE of the fishing fleet during the following season in the Gulf of California for (a) Elegant Terns $\left(r^{2}=0.37, n=23\right.$, $P=0.002)$ and (b) Heermann's Gulls $\left(r^{2}=0.30, n=23, P=0.007\right)$; and (c) linear relationship between proportion of Pacific Sardine in the seabirds' diet and CPUE of the fishing fleet during the same season for Brown Pelicans $\left(r^{2}=0.59, n=10, P=0.16\right)$. In all three cases, the value of the intercept was significantly greater than zero $(b>0)$, indicating that, when sardines in the diets reach zero the fleet is still harvesting significant amounts. The square data points correspond to El Niño years, when CPUE tends to decrease.

CPUEs even when seabirds have shifted entirely away in search of other fish species, mostly anchovies. Thus, even when CPUEs are high and there is no evidence of decreasing catchability in the fishery itself, other ecosystem components, such as seabirds, may be confronting a decline in available sardine. Availability may further decline during El Niño anomalies, when a deeper thermocline may prevent seabirds from reaching their prey. Thus, the El Niño anomaly (as expressed by the SOI values) and the relative abundance of sardine in the seabirds' diets can jointly predict the sardine CPUE by the commercial fleet.

Elegant Terns and Heermann's Gulls feed on pre-recruits of the small pelagic fish, while Brown Pelicans feed mostly on the same 

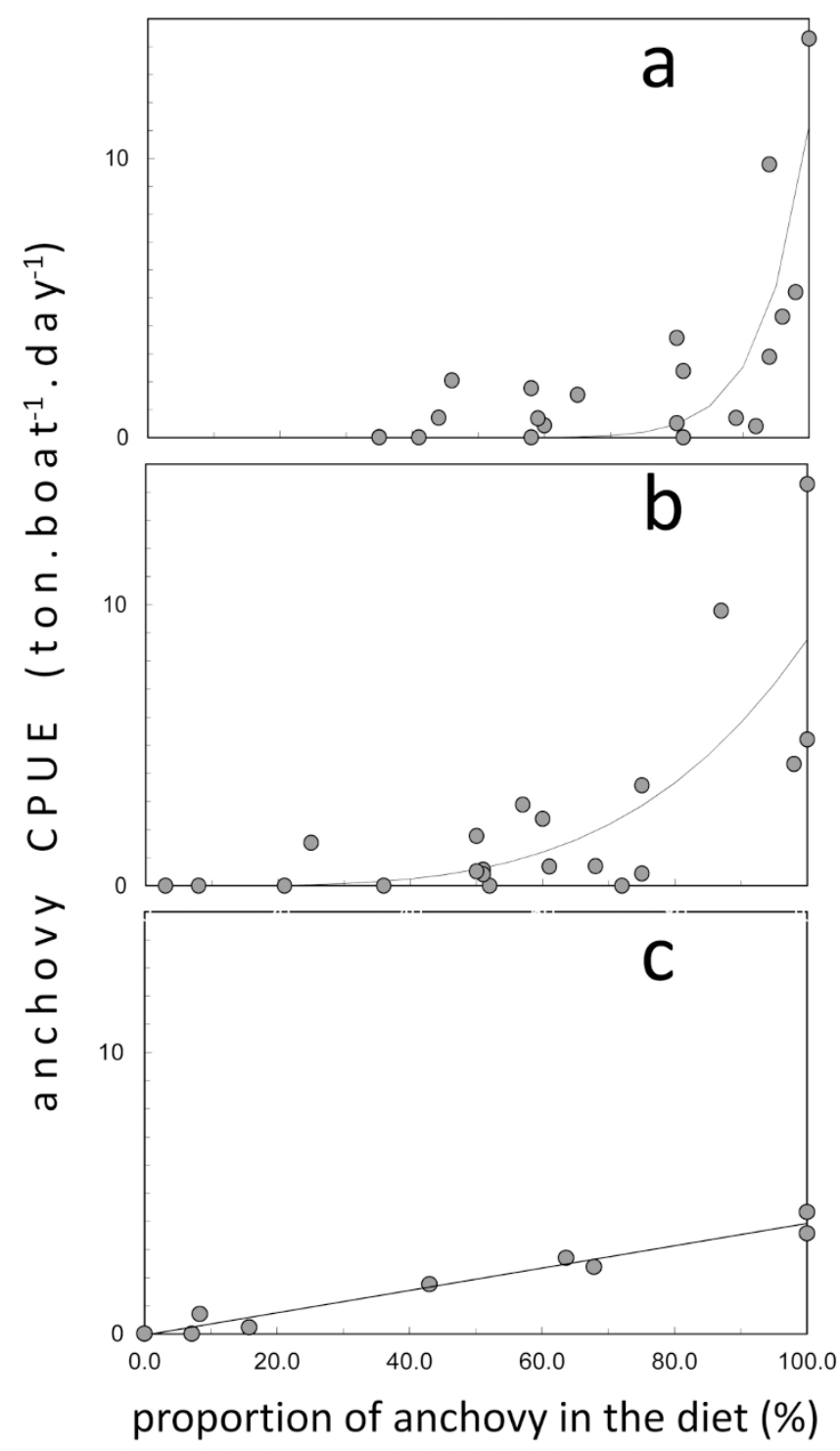

Figure 5 | Power-function relationship between proportion of Northern Anchovy in the seabirds' diet and CPUE of the fishing fleet during the following season in the Gulf of California for (a) Elegant Terns $\left(r^{2}=0.54\right.$, $n=23, P=0.0002)$ and (b) Heermann's Gulls $\left(r^{2}=0.53, n=21\right.$, $P=0.002)$; and (c) linear relationship between proportion of Northern Anchovy in the seabirds' diet and CPUE of the fishing fleet during the same season for Brown Pelicans $\left(r^{2}=0.96, n=10, P=0.0002\right)$. In the first two cases, the value of the exponent of the fitted power functions was significantly higher than unity $(b>1)$, making the fitted functions significantly concave.

adult fish that are taken by the fleet. This very likely explains why tern and gull diets are statistically more related to CPUEs in the following fishing season, while Brown Pelican diets are more related to CPUEs during the same season: Terns and gulls are taking juvenile prey that will be caught by the fleet months later, while the Pelicans are competing with the boats for the same adult fish.

The ability of tern and gull diets to provide a prediction of CPUEs before the beginning of the fishing season can be seen using the tern diet as a predictor of historic sardine CPUE (Fig. 6). Nesting Elegant Terns showed peaks in sardine consumption in the springs of 1988, 1996, 2001, and 2008, followed by a fall in the subsequent seasons. The fleet's CPUE fell one or two seasons later, as predicted by the lagged model of the tern's diet.
The capacity of the fleet to maintain high catches as sardine availability declines for other ecosystem components may be at the root of the fluctuations observed in the Gulf of California fishery. Strong fluctuations in landings, similar to what has been observed in this sardine fishery in the last decades, have been reported in other fisheries $^{19,20}$. It has been shown that fishing per se amplifies fluctuations in landings ${ }^{20,21}$ and theoretical models suggest these fluctuations are largely due to fishery-induced changes in the fishes' age structure, which become amplified by non-linear processes in the population dynamics $^{19,22}$.

In conclusion, sardine catchability is much higher for the fleet than it is for seabirds (and possibly for other ecosystem components). The increased sensitivity of the seabird diets relative to CPUE suggests that the seabirds are more diversified in their prey base and able to switch to other prey species when sardine availability starts to decline. Observed reductions in the proportion of sardines in seabirds' diets in the Gulf of California Midriff before the beginning of the fishing season may provide a useful way of monitoring the fishery and forecasting the success of the fishing fleet.

\section{Methods}

The proportion of Pacific Sardine and Northern Anchovy in the diet of Heermann's Gulls and Elegant Terns was estimated from seabird regurgitations all taken in springnesting colonies in Isla Rasa. For California Brown Pelicans, regurgitations were collected from chicks during banding operations led by the D. W. Anderson team in the islands Ángel de la Guarda, Piojo, San Lorenzo and Salsipuedes, all within the Midriff region, during May and June of 10 different years ${ }^{11}$. Not all sites were collected in all years, but due to the high mobility of these seabirds, we assumed that there were no large differences between their diets in the different islands. Samples from adult Heermann's Gulls and Elegant Terns were collected in Isla Rasa by the Velarde field team during 23 different years, as described in Velarde et al. ${ }^{9}$ (Supplementary Information Table 5). All field samples were taken under research and collecting permits granted by the Dirección General de Vida Silvestre (Mexico's National Wildlife Authority). Each food sample usually contained only one species of fish. Estimation of the proportion of each species in the diet was done using the number of regurgitations that contained each species of fish in relation to all the regurgitations collected. Data on total catch and CPUE for Pacific Sardines and Northern Anchovies were obtained from the official 1983-2011 statistics for the fishing fleet of Guaymas and Yavaros in the State of Sonora, which fishes mainly in the Guaymas Basin and the Gulf's Midriff region ${ }^{10,22}$. Finally, to estimate the intensity of the El Niño conditions we used the winter-springtime (January-May) Southern Oscillation Index (SOI) averaged for each year ${ }^{10}$. We downloaded the monthly values of the SOI index from the Commonwealth Bureau of Meteorology (available at www.bom.gov.au).

All statistical analyses were done using the R package $\mathrm{e}^{23}$. We first performed a lagged-correlation time series analysis between the proportion of the two most commonly captured pelagic fishes, the Pacific Sardine (Sardinops sagax) and the Northern Anchovy (Engraulis mordax), in the diets of the three seabird species and the fleet's CPUE of the same species. When the correlogram analysis showed a significant lag in the correlation between variables, i.e., when seabird diets in spring (April-June) showed the strongest correlations with CPUEs starting in late October of the same year and ending in summer of the following year, the analyses in the following sections were done on the lagged data series, using seabird diets during one season to regress against CPUEs the following season.

We developed two models to evaluate the relationship between seabird diets and the CPUEs. Our null assumption was that, if fish catchability for seabirds and CPUEs for the fleet varied in a similar manner, then they should show a simple linear relationship of the type: $C P U E=b$.diet, implying that when the seabirds cease to catch sardines the fleet will also see its CPUEs fall to zero. If, on the other hand, the fleet is still available to catch fish when seabirds cannot find them anymore, then the model will become: $C P U E=a+b$.diet, where the intercept $a$ represents the CPUE for the fleet when the proportion in the seabirds' diet becomes zero. In this model, if the intercept is positive we may conclude that the fishery is more stable for the fleet than it is for the birds, as the fleet will still be able to catch fish when the seabirds have moved on to other prey.

Alternatively, when the relationship between CPUEs and the proportion of fish in the seabird diets is significantly curvilinear (the linear regression model fails the tests for independence of the residuals), a power-function model may be fitted between the proportion of a prey in the diet of the seabirds and the catch per unit effort (CPUE) of the fleet, using non-linear estimation ${ }^{23}$. The power exponents $(z)$ of the fitted curves are "allometric scaling" parameters that measure how one variable scales up or down when another variable changes ${ }^{24}$. The exponents of our analyses were tested for significance under the null hypothesis that $z=1$, i.e., that the relationship between anchovy in the seabirds' diet and CPUE is linear with zero intercept $(C P U E=b$.diet $)$, and hence, that the availability of anchovies in the sea scales similarly for both the seabirds and the fleet. Power-function models are used commonly in fishery science to test the relationship between CPUE and fishery-independent estimates of the 

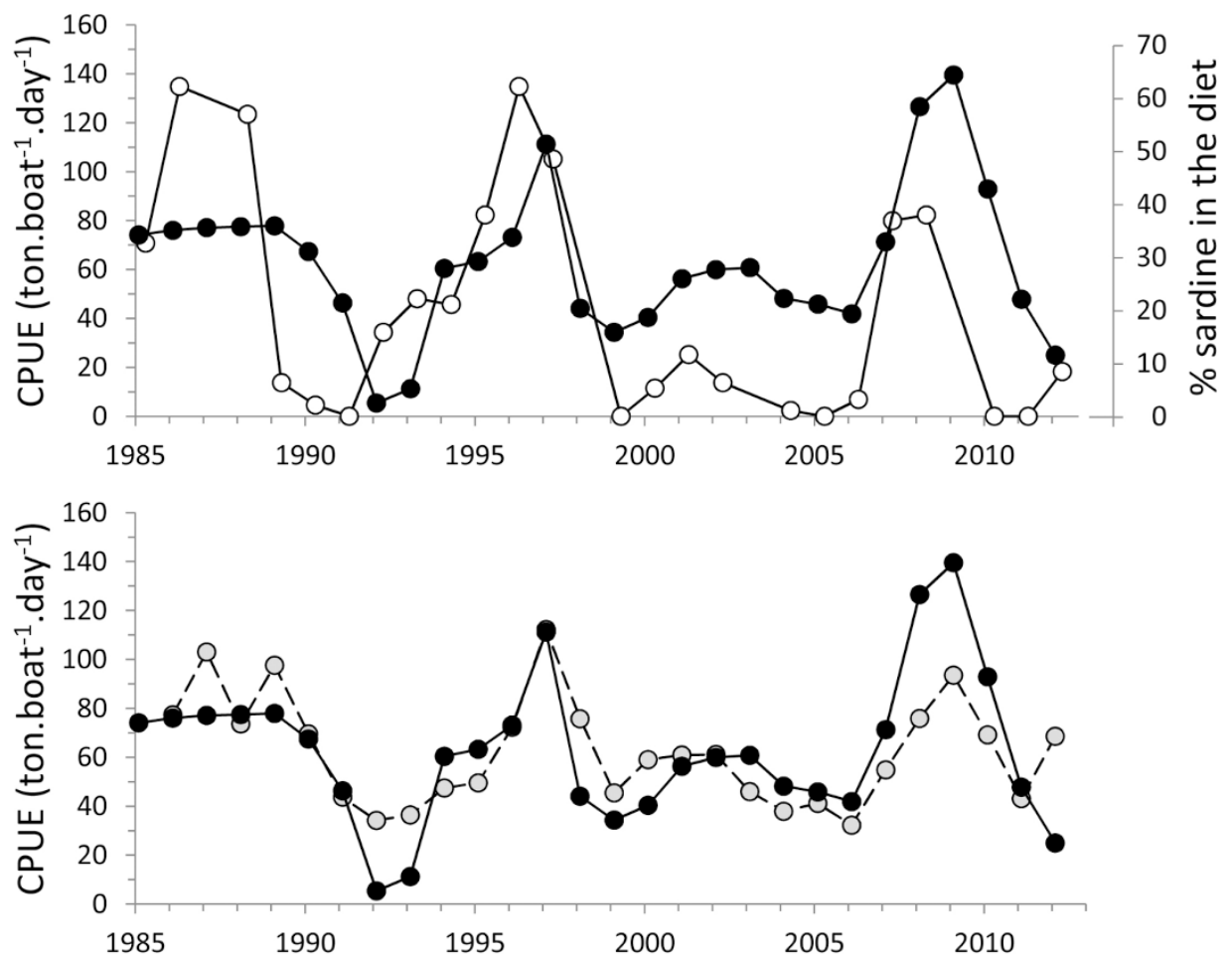

Figure $6 \mid$ (top) Proportion of Pacific Sardine in the Elegant Terns' diet between 1985 and 2011 (open data-points) and fleet CPUEs (ton.boat ${ }^{-1}$.day ${ }^{-1}$ ) for the same period (black data points). Note the clear one-season lag between both data sets. (bottom) Fleet CPUEs between 1985 and 2011 (black points) and values predicted (gray points) by the Southern Oscillation Index and the proportion of Pacific Sardine in the terns' diet in the previous season $\left(r^{2}=0.51\right)$.

stock $^{12,15}$. After fitting both models, the best model was selected using Akaike's Information Criterion (AIC) $)^{23}$.

Lastly, in order to test the added effect of environmental anomalies on the fishery, we regressed the fleet's CPUE against both the seabird diets (linear or powertransformed according to the previous analysis) and the annual averaged Southern Oscillation Index (SOI), an indicator of the status of the warm-phase oscillation in the Pacific Ocean. This model predicts CPUE using two basic indicators: (a) the relative abundance of sardine or anchovy in the seabird diets at the Gulf's Midriff, and (b) the status of the oceanographic conditions that drive marine productivity in the region by affecting sea surface temperatures, intensity of upwelling, and depth of the thermocline.

1. Pikitch, E. et al. Little Fish, Big Impact: Managing a Crucial Link in Ocean Food Webs. Lenfest Ocean Program. Washington, DC. pp. 108 (2012).

2. Botsford, L. W., Castilla, J. C. \& Peterson, C. H. The management of fisheries and marine ecosystems. Science 277, 509-515 (1997).

3. Schwartzlose, R. A. et al. Worldwide large-scale fluctuations of sardine and anchovy populations. S. Afr. J. Marine Sci. 21, 289-347 (1999).

4. Sánchez-Velasco, L., Shirasago, B., Cisneros-Mata, M. A. \& Ávalos-García, C. Spatial distribution of small pelagic fish larvae in the Gulf of California and its relation to the El Niño 1997-1998. J. Plankton Res. 22, 22-29 (2000).

5. Rykaczewski, R. R. \& Checkley, D. M. Influence of ocean winds on the pelagic ecosystem in upwelling regions. P. Natl. Acad. Sci. USA 105, 1965-1970 (2008).

6. Cury, P. M. et al. Global Seabird Response to Forage Fish Depletion-One-Third for the Birds. Science 334, 1703-1706 (2011).

7. Cury, P. M. et al. Small pelagic in upwelling systems: patterns of interaction and structural changes in "wasp-waist" ecosystems. ICES J. Mar. Sci. 57, 603-618 (2000).

8. Vieyra, L., Velarde, E. \& Ezcurra, E. Effects of parental age and availability of small pelagic fish on the reproductive success of Heermann's Gulls in the Gulf of California. Ecology 90, 1084-1094 (2008).

9. Velarde, E., Tordesillas, M. S., Vieyra, L. \& Esquivel, R. Seabirds as indicators of important fish populations in the Gulf of California. Cal. Coop. Ocean. Fish. 35, 137-143 (1994).

10. Velarde, E., Ezcurra, E., Cisneros-Mata, M. A. \& Lavín, M. F. Seabird ecology, El Niño anomalies, and prediction of sardine fisheries in the Gulf of California. Ecol. App. 14, 607-615 (2004).

11. Anderson, D. W., Gress, F., Mais, K. F. \& Kelly, P. R. Brown pelicans as anchovy stock indicators and their relationships to commercial fishing. Cal. Coop. Ocean. Fish. 21, 54-61 (1980).
12. Hilborn, R. \& Walters, C. J. Quantitative fisheries stock assessment: Choice, dynamics and uncertainty. Chapman and Hall, New York, USA (1992).

13. Rose, G. A. \& Kulka, D. W. Hyperaggregation of fish and fisheries: How catch-perunit-effort increased as the northern cod (Gadus morhua) declined. Can. J. Fish. Aquat. Sci. 56, (Supplement1), 118-127 (1999).

14. Montevecchi, W. A. \& Myers, R. A. Prey harvests of seabirds reflect pelagic fish and squid abundance on multiple spatial and temporal scales. Mar. Ecol.-Prog. Ser. 117, 1-9 (1995).

15. Erisman, B. E. et al. The illusion of plenty: hyperstability masks collapses in two recreational fisheries that target fish spawning aggregations. Can. J. Fish. Aquat. Sci. 68(10), 1705-1716 (2011)

16. Crawford, R. J. M. \& Dyer, B. M. Responses by four seabird species to a fluctuating availability of Cape anchovy Engraulis capensis off South Africa. Ibis 137, 329-339 (1995).

17. Crawford, R. J. M. Responses of African Penguins to regime changes of sardine and anchovy in the Benguela System. S. Afr. J. Marine Sci. 19, 355-364 (1998).

18. Vieyra, L., Velarde, E. \& Ezcurra, E. Effects of parental age and food availability on the reproductive success of Heermann's Gulls in the Gulf of California. Ecology 90 , 1084-1094 (2009).

19. Anderson, C. N. K. et al. Why fishing magnifies fluctuations in fish abundance. Nature 452(7189), 835-839 (2008).

20. Hsieh, C. et al. Fishing elevates variability in the abundance of exploited species. Nature 443, 859-862 (2006).

21. Beddington, J. R. \& May, R. M. Harvesting natural populations in a randomly fluctuating environment. Science 197, 463-465 (1977).

22. Cisneros-Mata, M. A., Montemayor-López, G. \& Nevárez-Martínez, M. O. Modeling deterministic effects of age structure, density dependence, environmental forcing and fishing in the population dynamics of the Pacific Sardine (Sardinops sagax caeruleus) stock of the Gulf of California. Cal. Coop. Ocean. Fish. 37, 201-208 (1996).

23. R Development Core Team. $R$ : A language and environment for statistical computing. Version 2.15.2 (2012-10-26). R Foundation for Statistical Computing, Vienna, Austria (2012). http://www.R-project.org.

24. De Martino, S. \& De Siena, S. Allometry and growth: A unified view. Physica A 391, 4302-4307 (2012).

\section{Acknowledgments}

We acknowledge Mexico's Dirección General de Vida Silvestre, Comisión Nacional de Áreas Naturales Protegidas, and Secretaría de Gobernación for research and collecting permits. The Mexican Navy has kindly provided support for marine transportation to and from Isla 
Rasa during all these years. Support for this research has come from many sources throughout the duration of the work, most importantly from Baja Expeditions, Comision Nacional para el Conocimiento y Uso de la Biodiversidad, Consejo Nacional de Ciencia y Tecnología, Conservation International, International Community Foundation, Fondo Mexicano para la Conservación de la Naturaleza, Instituto Nacional de Ecología,

International Council for Bird Preservation, International Foundation for the Conservation of Birds, Lindblad Expeditions, National Geographic Society, Packard Foundation, Programa PROMEP (Secretaría de Educación Pública), UC MEXUS, San Diego Natural History Museum, The Living Desert, The Nature Conservancy, Unidos para la Conservación/Agrupación Sierra Madre, Universidad Veracruzana, University of California, U.S. Fish and Wildlife Service, Universidad Nacional Autónoma de México, Ruth Applegarth, Sue Adams, and an anonymous donor. We acknowledge the support of the Walton Family Foundation and Comunidad y Biodiversidad, A.C., for their support for this publication. We thank the following institutions and people for providing fisheries data: Miguel Ángel Cisneros-Mata, Manuel O. Nevares, María de los Ángeles Martínez Zavala from CRIP-Guaymas, Instituto Nacional de la Pesca, and, very especially, León Tissot, President of the Cámara de la Industria Pesquera de Sonora, who kindly provided data on the fishery. We also thank Brad Erisman and Octavio Aburto, from Scripps Institution of Oceanography, for introducing us to the theory of fisheries' hyperstability and CPUE power-function models. Dozens of students and volunteers have helped with field work and data collection.

\section{Author contributions}

D.A. did the field work with pelicans and initially invited the group to do this collaborative analysis. E.V. conducted the field work with gulls and terns. E.E. and E.V. analysed the data, wrote the manuscript, and developed the figures. All three authors reviewed and edited the manuscript.

\section{Additional information}

Supplementary information accompanies this paper at http://www.nature.com/ scientificreports

Competing financial interests: The authors declare no competing financial interests.

License: This work is licensed under a Creative Commons

Attribution-NonCommercial-NoDerivs 3.0 Unported License. To view a copy of this license, visit http://creativecommons.org/licenses/by-nc-nd/3.0/

How to cite this article: Velarde, E., Ezcurra, E. \& Anderson, D.W. Seabird diets provide early warning of sardine fishery declines in the Gulf of California. Sci. Rep. 3, 1332; DOI:10.1038/srep01332 (2013) 